\title{
Double fistula between esophagus and mediastinum during chemo-radiotherapy in a patient affected with esophageal
}

\section{cancer}

\author{
Elena Bolzacchini*, Alessandro Tuzi and Graziella Pinotti \\ U.O Oncologia Medica, Azienda ospedaliero-universitaria Ospedale di Circolo e Fondazione Macchi, Italy
}

A 61 years-old woman received the diagnosis of cervical esophageal stenosing cancer in September 2015. An esophageal stent was endoscopically placed at the diagnosis. The patient was treated by concomitant chemotherapy (weekly carboplatin AUC2 and paclitaxel $50 \mathrm{mg} / \mathrm{m}^{2}$ ) and radiotherapy (41.4 Gy) completed in Dicember 2015. In February 2016 the patient complained cough; an X-ray was performed and was suspicious for pneumonia with multiple foci. Computed tomography (CT) was scheduled with administration of intravenous contrast and administration of hydrosoluble contrast per os. CT showed a large consolidation in the right lung with air-fluid level and the presence of a leak of contrast between the esophageal lumen and the collection for the presence of a fistula (Figure 1: a, b, c). Another smaller para-esophageal collection was also recognizable in the upper third of the esophagus with air-fluid level; at this level there was another leak of contrast for the presence of a second fistula (Figure 1.d). The patient was considered inoperable and she was treated only with palliative/supportive care.

The incidence of fistula in esophageal cancer is reported in the range of $5 \%$ to $13 \%$. [1-2]

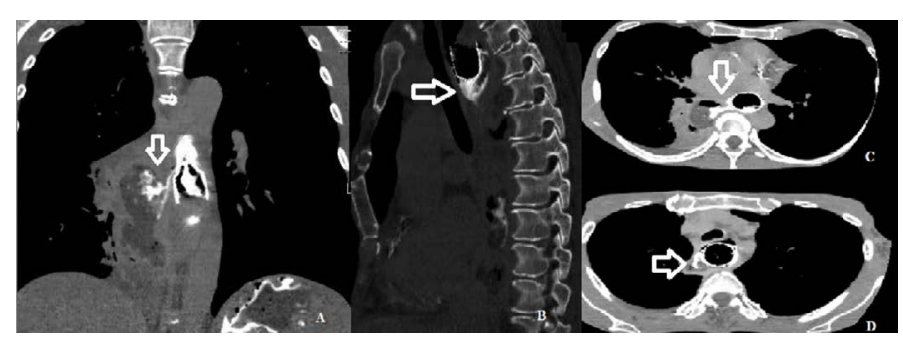

Figure 1 a, b, c. CT scan of the thorax (a coronal scan, b sagittal scan, c axial scan) that shows a consolidation in the right lung $(7 \times 4 \times 13 \mathrm{~cm})$ with air-fluid level and a the presence of a leak of contrast between the esophageal lumen and the collection for the presence of a fistula. d. CT axial scan of the thorax that shows another para-esophageal collection in the upper third of the esophagus with air-fluid level $(2,5 \times 1,5 \times 3,5 \mathrm{~cm})$, also at this level there was a leak of contrast for the presence of fistula.

Copyright: (C)2017 Bolzacchini E. This is an open-access article distributed under the terms of the Creative Commons Attribution License, which permits unrestricted use, distribution, and reproduction in any medium, provided the original author and source are credited.
Esophagobronchial fistula could be caused by direct neoplastic infiltration and necrosis between the esophagus, bronchus, and mediastinum or could also be induced by necrosis or cytoreduction of the tumor. There is no clear evidence that multimodal treatment increase the incidence of fistula formation [3], however development of fistula during concomitant chemo-radiotherapy in patients affected by esophageal and lung cancer is reported. [3-4]

The peculiarity of our case is the occurrence of two fistulas during chemo-radiotherapy. The main symptoms are cough, dyspnea and fever due to pneumonia, which is often recurrent [5]. The development of an esophagobronchial fistula is a devastating and life-threating complication; therapeutic modalities comprehends surgical resection, endoscopic placement of self-expandable covered stents and non-invasive supportive/palliative therapy. [4-5]. Our patient was considered inoperable and the development of this complication was fatal.

\section{References}

1. Martini N, Goodner JT, D'Angio GJ, Beattie EJ (1970) Tracheoesophageal fistula due to cancer. J Thorac Cardiovasc Surg 59: 319-324.

2. 2.Duranceau A, Jamieson GG (1984) Malignant tracheoesophageal fistula. Ann Thorac Surg 37: 346-354. [Crossref]

3. Ozeki T, Asano M, Fujimoto N, Nishimura J, Takada K, et al. (2017) Esophagobronchial Fistula in a Patient with Squamous Cell Carcinoma of the Lung: A Case Report. Case Rep Oncol 10:553-557. [Crossref]

4. Rehders A, Baseras B, Telan L, Al-Sharahbani F, Angenendt S, et al. (2014) Esophageal cancer complicated by esophagopulmonary fistula and lung abscess formation: A surgical approach. Thorac Cancer 5: 468-471. [Crossref]

5. 5.Rodriguez AN, Diaz-Jimenez JP (2010) Malignant respiratory-digestive fistulas. Curr Opin Pulm Med 16:329-333. [Crossref]
Correspondence to: Elena Bolzacchini, U.O Oncologia Medica, Azienda ospedaliero-universitaria Ospedale di Circolo e Fondazione Macchi, Viale Borri, 5721100 Varese, Italy, Tel: 00393298597540; Fax: 0332/278673; E-mail: elena. bolzacchini@hotmail.it

Key words: esophageal cancer, fistula, chemo-radiotherapy

Received: November 02, 2017; Accepted: November 27, 2017; Published: November 30, 2017 